\title{
ENTRE SOFRIMENTO E PRAZER: VIVÊNCIAS NO TRABALHO DE INTERVENÇÃO EM CRISES SUICIDAS ${ }^{1}$
}

\author{
Silvanir Destefani Sartori ${ }^{2}$ \\ Eloisio Moulin de Souza ${ }^{3}$
}

http://dx.doi.org/10.1590/1413-2311.203.78656

\section{RESUMO}

A Psicodinâmica do Trabalho considera que o trabalho pode ser fonte de prazer e sofrimento, variando de acordo com as imposições de sua natureza. A partir disso o objetivo deste trabalho/ensaio é compreender as vivências de prazer e sofrimento de trabalhadores em uma organização, face o atendimento de ocorrências envolvendo crises suicidas. Para o alcance desse objetivo foram entrevistados 15 (quinze) trabalhadores que atenderam ocorrências dessa natureza em uma organização de trabalho localizada no sudeste do Brasil. Esses trabalhadores lidam com as imposições da complexidade da crise suicida integrantes das condições de trabalho, ao tempo que buscam experimentar prazer nos espaços permitidos a sua expressão por meio do emprego de sua inteligibilidade e na premissa do reconhecimento. As vivências de sofrimento e prazer foram compreendidas em linha tênue constantemente transpassada e demarcada pelas características e comportamento da vítima em conflito, em oposição a busca dos trabalhadores em se manifestar perante as imposições do trabalho.

Palavras-Chave: Psicodinâmica do Trabalho. Suicídio. Sofrimento. Prazer. Atendimento de ocorrências.

\footnotetext{
${ }^{1}$ Recebido em 11/12/2017, aceito para publicação em 21/06/2018.

${ }^{2}$ Universidade Federal do Espírito Santo (Vitória, ES, Brasil) - silvanirdestefani@yahoo.com.br

${ }^{3}$ Universidade Federal do Espírito Santo (Vitória, ES, Brasil) - eloisiomoulin@gmail.com
} 


\title{
BETWEEN SUFFERING AND PLEASURE: WORK EXPERIENCES OF SUICIDAL CRISIS INTERVENTION
}

\begin{abstract}
Labor psychodynamics considers that work can be source of pleasure and suffering, varying according to its nature impositions. This way, the object is to comprehend, in light of Labor Psychodynamics, the experiences of pleasure and suffering of workers in an organization due to the attending of occurrences involving suicidal crisis. In order to accomplish this, 15 (fifteen) workers that attended occurrences of this nature in a labor organization located in Southeast Brazil were interviewed. These workers deal with the impositions of suicidal crisis complexity, while they search to experience pleasure in spaces allowing their expression by the use of their intelligibility and in the premise of recognition. The experiences of suffering and pleasure were comprehended in a fine line constantly transposed and limited by the victim's characteristics and behavior in conflict in opposition to the search of workers in demonstrating towards labor impositions.
\end{abstract}

Key words: Labor Psychodynamics. Suicide. Suffering. Pleasure. Attending of occurrences.

\section{ENTRE EL SUFRIMIENTO Y EL PLACER: LA EXISTENCIA EN EL TRABAJO DE LA INTERVENCIÓN EN LAS CRISIS SUICIDAS}

\begin{abstract}
RESUMEN
Psicodinámica del trabajo considera que el trabajo puede ser fuente de placer y sufrimiento, variando de acuerdo con las imposiciones de su naturaleza. Con eso, el objetivo es comprender la luz de la Psicodinámica del trabajo, la existencia de placer y sufrimiento de los trabajadores en una organización, teniendo en cuenta los hechos que involucran las crisis suicidas. Para alcanzar ese objetivo fueron entrevistados 15 (quince) trabajadores que habían pasado por situaciones de esa naturaleza en una organización de trabajo ubicado en el sureste de Brasil. Esos trabajadores conviven con la dificultad de crisis suicida a consecuencia de las condiciones de trabajo, al mismo tiempo que buscan disfrutar en los espacios permitidos por medio de su comprensión y en la premisa del reconocimiento. La existencia de sufrimiento y placer fueron comprendidos en una línea tenue constantemente traspasada y
\end{abstract}


demarcada por las características y el comportamiento de la víctima en conflicto en oposición a la búsqueda de los trabajadores que se manifiestan delante de las imposiciones del trabajo.

Palabras-clave: Psicodinámica del trabajo. el suicidio. el sufrimiento. el placer. el atendimiento de los acontecimientos.

\section{INTRODUÇÃO}

A morte por suicídio, compreendida como ato voluntário e intencional em que o próprio indivíduo busca dar fim a sua vida, envolve tabu, preconceito, julgamentos e causa desconforto no meio social. Por muitas vezes o debate, a respeito do tema aqui analisado, está restrito a esfera privada (MELEIRO; BAHLS, 2004; DEJOURS; BÈGUE, 2010). Especificamente quando se analisa trabalhadores responsáveis pela intervenção em crises suicidas, a fim de salvar a vítima, verifica-se que estes são afetados e vivenciam sofrimento, sendo considerados sobreviventes.

Este sofrimento é oriundo do confronto da livre iniciativa dos trabalhadores e suas crenças com as condições impostas pelo trabalho, tornando a atividade laboral exercida percursora de perigo ao aparelho psíquico. Pois trata-se de uma relação em que a organização do trabalho se manifesta como a vontade do outro, despossuindo o trabalhador de seu corpo físico e nervoso, domesticando-o e forçando-o a agir conforme exigências dessa organização, seja através de excitações exógenas e/ou endógenas (DEJOURS, 1994).

Esse mesmo trabalho propulsor de sofrimento também é lugar de prazer, experimentado por meio da descarga psíquica nos espaços permitidos pela organização de trabalho. Neste caso, o trabalho não assume necessariamente a condição de infelicidade e/ou sofrimento, podendo vir a ser operador de saúde em que certos sujeitos estarão melhor estabelecidos mediante a sua inserção no mundo do trabalho. Esta condição de coexistência de prazer e sofrimento é proveniente da dinâmica interna das situações e da organização do trabalho, sendo objeto de estudo da Psicodinâmica do Trabalho (DEJOURS; ABDOUCHELI; JAYET, 1994).

Nesse contexto, o objetivo deste artigo é compreender à luz da psicodinâmica do trabalho as vivências de prazer e sofrimento de trabalhadores em uma organização de trabalho, face a intervenção em ocorrências envolvendo suicídio. São sujeitos dessa análise 
trabalhadores inseridos em uma organização de trabalho pública localizada na região Sudeste do Brasil a qual possui por atribuição, entre outras atividades, intervir em crises suicidas a fim de retirar a vítima de qualquer risco contra sua própria vida.

A realização dessa pesquisa é justificada por se configurar como um instrumento de voz aos trabalhadores que sofrem no trabalho, rompendo com a barreira do silêncio herdada no processo de constituição do trabalhador brasileiro, acostumado a se silenciar quanto suas demandas. Assim, pesquisar sofrimento e prazer no trabalho, é também compreender a existência e influência dessas vivências em estratégias laborais e de integração social retirando os trabalhadores da invisibilidade (DUARTE; MENDES, 2015; CASTEL, 1998; DEJOURS, 2011a). Além disso, é importante evidenciar que os trabalhadores investigados não são afetados apenas pela crise suicida, mas também pela forma como o trabalho se organiza (DEJOURS, 2000). Inobstante, a compreensão de atuarem os trabalhadores sujeitos dessa pesquisa na retirada da vítima do local de risco na perspectiva de salvar a vítima contribui para com as pesquisas existentes, uma vez que mais pesquisas consideram trabalhadores inseridos no contexto hospitalar, em que contrariamente as vivências compreendidas nesse artigo, denotam resistência a atender vítimas de suicídio, além de por vezes o paciente ser recebido nesses serviços com agressividade e revolta (BERTOLOTE; MELLO-SANTOS; BOTEGA, 2010; SRIVASTAVA; TIWARI, 2012; CREPALDI, 2012). Evidencia que mesmo o suicídio sendo ato voluntário, atinge toda uma coletividade, inclusive trabalhadores que se inserem nesse contexto a fim de atender a vítima (WORLD HEALTH ORGANIZATION, 2014).

Para atingir a compreensão do objetivo proposto serão a seguir apresentados conceitos da categoria teórica da Psicodinâmica do Trabalho. Logo após apresentar-se-á as especificidades deste trabalho e o processo pelo qual os trabalhadores são tornados sobreviventes. Posteriormente é apresentada a metodologia delineadora da pesquisa, a qual culmina na compreensão do objetivo proposto por meio da análise dos dados produzidos relacionados as vivências de prazer e sofrimento. O que levou as considerações finais do artigo em que o intervir em crises suicidas representa uma linha tênue entre o prazer e o sofrimento.

\section{A PSICODINÂMICA DO TRABALHO}

Tendo por percursor Christophe Dejours, a Psicodinâmica do Trabalho tem por objeto de pesquisa a vida psíquica no trabalho com ênfase no sofrimento e na transformação do 
trabalho em fonte de prazer (DEJOURS, 2011a). A Psicodinâmica compreende que nos espaços de liberdades existentes na organização de trabalho, o trabalhador busca adaptação as condições impostas, alcançando equilíbrio psíquico. Assim, se há liberdade e consequente livre escolha por parte do trabalhador, a carga psíquica é liberada tornando o trabalho também fonte de prazer. Quando essa liberdade é suprimida há aumento da carga psíquica surgindo o sofrimento que atinge a saúde física e psíquica do trabalhador (BENDASSOLLI; SOBOLL, 2011; CARMO; GUIMARÃES; CAEIRO, 2016; DEJOURS, 2007).

Dessa maneira, o prazer e o sofrimento para a Psicodinâmica do Trabalho se fazem presentes de forma simultânea no trabalho, pois ao mesmo tempo em que o trabalho pode ser estruturante e promover dignidade, pode também ser alienante e levar ao adoecimento. Neste caso, o sofrimento surge quando acontece supressão do espaço existente entre organização de trabalho e trabalhador, bloqueando essa relação e provocando o domínio e a luta contra o sofrimento. Este sofrimento pode ser oriundo de sentimentos gerados por aspectos que atingem a organização e se manifestam pelo engajamento do corpo, pelas relações com os outros e pela apropriação/espoliação da intelectualidade dos trabalhadores pela organização (MEDEIROS; MENDES, 2013; DEJOURS, 1994; 2011b; ALVES, 2011).

Logo, o sofrimento advém do confronto do sujeito com o real do trabalho e na convivência do trabalhador com aspectos objetivos da atividade que por vezes incluem fadiga, excesso de regras, ocorrência de eventos inesperados, interrupções motivadas por colegas de trabalho e/ou patrão, rigidez hierárquica, padronização de tarefas, subutilização do potencial técnico, falta de participação em decisões e baixa perspectiva de crescimento profissional. São situações em que o sujeito se encontra submetido a ritmos e condições impeditivas de se manifestar, e em virtude dessa impossibilidade a pressão exercida pela organização de trabalho transforma as vivências de trabalho em sofrimento, podendo inclusive representar risco de adoecimento (DASHTIPOUR; VIDAILLET, 2017; ANTLOGA; MENDES; MAIA, 2012; DEJOURS, 2007; BARROS; HONÓRIO, 2015). Na contrapartida, as vivências de prazer se consolidam em razão do trabalhador ser habitado pelo desejo de realização e singularidade/identidade, levando-o a querer oferecer sua contribuição social. O prazer ocorre geralmente quando o trabalhador goza de liberdade frente às exigências impostas pela organização do trabalho para negociar suas necessidades e desejos, propiciando o reconhecimento de sua contribuição no trabalho realizado (MENDES; VIEIRA, 2014; MÁXIMO; ARAÚJO; SOUZA, 2014).

O reconhecimento é concretizado perante o olhar do outro sobre o trabalho contribuindo para a construção da identidade no trabalho e, consequentemente, contribui na 
constituição do trabalhador enquanto sujeito. Quando inexiste experimentação de reconhecimento pelo trabalhador isso é compreendido como desvalorização consolidando-se como vivência de sofrimento. Essa premissa de reconhecimento se faz no sentido de constatação e ocorre em virtude da contribuição individual específica a organização do trabalho, denotando resistência a hierarquia imposta ao evidenciar a imperfeição do prescrito. O reconhecimento também é sentido enquanto gratidão, sendo que nesse caso se aproxima da literalidade da palavra por se concretizar à medida que a organização de trabalho ou a sociedade reconhece a contribuição dos trabalhadores (LANCMAN, 2011; ALDERSON, 2004; DEJOURS, 2011c). Significa afirmar que o trabalho representa mais do que venda de força para sobreviver, mas também remuneração social e singularidade do sujeito em sua relação com o outro (LANCMAN, 2011; MATTOS; SCHLINDWEIN, 2015).

A complexidade dessa relação e a polivalência das situações reais de trabalho faz com que sofrimento e prazer estejam em linhas limítrofes, em espaços de luta, sendo a busca por prazer e o afaste do sofrimento permanentes (DEJOURS, 2011b; MENDES, 1995). Estas vivências de prazer e sofrimento ocorrem no hiato entre a organização de trabalho prescrita e real as quais existem devido aos imprevistos e contradições inerentes as relações humanas e sociais concretizadas no trabalho serem impeditivas da absoluta prescrição do real (MENDES; VIEIRA, 2014). Assim, implica a organização real no afastamento das prescrições para que a atividade possa ser executada, representando imprescindíveis espaços para a expressão do trabalhador e consequente manutenção de seu equilíbrio psíquico.

Esse distanciamento do prescrito acontece devido a atividade humana de interpretação na execução do trabalho ocasionar situações de desconhecimento e inépcia face às dificuldades concretas com que se deparam os trabalhadores. São nesses espaços que a atividade produtiva acontece, sendo resultante da inteligência do trabalhador circunscrito em uma espécie de resistência aos procedimentos padronizados (DEJOURS, 2011a; 2011c). Todavia, apesar desse distanciamento ser inevitável e até mesmo imprescindível à execução do trabalho, o próprio trabalhador reivindica por norteamento (prescrição) a fim de que atenue a sensação e percepção de risco e das contrariedades do real, buscando impedir a consciência aguda do risco (DESSORS; SCHRAM, 1992). Por conseguinte, a organização prescrita é de orientação normativa e relaciona-se à disciplina, compreendendo as normas estritamente funcionais sem quaisquer valorações. Esta organização prescrita face ao fator humano e a construção social na execução do trabalho é evolutiva, pois ultrapassa os imperativos e as prescrições da técnica do trabalho (DEJOURS; ABDOUCHELI; JAYET, 1994; MENDES, 1995). 
Indubitavelmente o foco desse artigo está na organização real do trabalho, visto que o suicídio produz efeitos no trabalho. Por consequência, para se entender este fenômeno, utiliza-se a Psicodinâmica do Trabalho em razão desta ter por objeto os processos intersubjetivos que tornam possíveis a gestão das interpretações do sofrimento e prazer do trabalho pelos sujeitos (DEJOURS, 2011a). Esses sujeitos mediante a execução de tarefas exigentes de um trabalho coletivo, de se ter conhecimento do sentido do trabalho e de essas dimensões serem sentidas e compartilhadas coletivamente, compõe um coletivo de trabalho. A existência desse coletivo resulta na adesão do trabalhador a costumes, regras, medos em esfera coletiva, implicando ser o trabalho também espaço de viver juntos (DEJOURS, 2000; TSCHIEDEL; MONTEIRO, 2013).

Ao se compreender a organização real na intervenção em crises suicidas as nuances das crises dessa natureza fluem significativamente no trabalho daqueles que intervém a fim de salvar a vítima, propiciando vivências de prazer e sofrimento. Para atingir essa compreensão é apresentada a seguir a relação entre o trabalho e trabalhadores, destacando como o trabalho de intervenção em crises suicidas acontece, caracterizando estes trabalhadores como sobreviventes.

\section{O TRABALHO E OS TRABALHADORES}

O coletivo de trabalhadores pesquisados tem sido cada vez mais demandado em decorrência do aumento de casos de suicídio (FREITAS; BORGES, 2014). Ao atender essa demanda os trabalhadores lidam com condições e características impostas pela complexidade da crise suicida, compreendida como processos exigentes de metodologia própria que estão além dos padrões das ciências exatas, sendo cada crise suicida peculiar e diferenciada uma das outras por detalhes que a constituem por um caráter único. Representam vivências com a necessidade de se distinguir, tomar decisão, separar e julgar condições que influenciam o trabalho e repercutem em vivências de prazer e sofrimento (COIMBRA, 2011; BOTEGA, 2015).

Essa vivência perante a crise suicida pode ser dolorosa variando de acordo com a gravidade envolvida, além de poder levar a experimentação de angústia, desamparo, incapacidade e esgotamento. Em níveis extremos poderá levar a colapso existencial ultrapassando a capacidade pessoal de reação e adaptação, pode aumentar a vulnerabilidade para o suicídio, contudo, em alguns casos, poderá ser considerada útil quando o significado 
do inesperado for integrado à história do sujeito possibilitando uma nova perspectiva de vida (BOTEGA, 2015).

Em face dessas condições, os trabalhadores sujeitos desse artigo são considerados sobreviventes, uma vez que ao trabalhar objetivando intervir na crise suicida para salvar a vítima, inevitavelmente, são afetados tendo suas vidas marcadas pela complexidade, extremidade e agressividade do ato (TAVARES, 2013).

Este trabalho de intervenção consiste no deslocamento dos trabalhadores ao local onde a vítima se coloca intencionalmente em risco de morte, como por exemplo, pontes, prédios, torres (meio letal: defenestração em altura) e a própria residência da vítima (meio letal: ingestão de substâncias tóxicas, uso de arma de fogo e enforcamentos). O emprego do meio letal varia de acordo com a frequência e o acesso que se tem a eles, sendo influenciado pela própria organização e estrutura dos espaços onde as pessoas vivem (WORLD HEALTH ORGANIZATION, 2014).

A depender do meio letal empregado o trabalho de intervenção na crise suicida é caracterizado pelos trabalhadores como possível de ocorrer seguindo duas metodologias: negociação ou abordagem física. Assim, a intervenção pode ser iniciada com a tentativa de negociação, mas em virtude do risco iminente ou do comportamento da vítima a mesma pode findar com a abordagem física. A negociação consiste em estabelecer diálogo com a vítima na tentativa de criar vínculo e convencê-la a interromper o ato, enquanto a abordagem física ocorre quando a vítima será tirada de risco por meio do emprego de apuradas técnicas de resgate, agarrando-a com uso de força. Ambas as metodologias são empregadas mediante a observância de medidas de segurança ao trabalhador, objetivando atenuar a consciência aguda do risco de acidentes que seria impeditiva do trabalho ser executado (COIMBRA, 2011; DEJOURS, 2000). Diante dessas possibilidades de intervenção os trabalhadores que intervêm em atos suicidas defendem que o primeiro passo deve ser pelo emprego da negociação, pois estabelecer vínculo com a vítima repercute positivamente em como ela responderá ao cuidado oferecido após a intervenção. Entretanto, em situações onde o risco de morte é iminente e a vítima pode até mesmo vir a óbito ou sofrer graves lesões acidentalmente (escorregar, por exemplo), ou ainda quando a tentativa de convencimento não progride, é utilizada a abordagem física (VIDAL; GONTIJO, 2013).

A partir dos comentários dos trabalhadores este trabalho de intervenção é concebido em quatro etapas: (1) o recebimento do comunicado da ocorrência, compreendido no ato de alguém presente no local, acionar os trabalhadores através de uma central telefônica; (2) o deslocamento até o local quando se inicia o gerenciamento da crise na busca de maiores 
informações das circunstâncias do local, meio letal empregado e condição da vítima; (3) a preparação para intervenção, na realização de divisão de tarefas, análise das condições e adoção de medidas de segurança (interrupção de tráfego de veículos, ancoragem ou amarração do trabalhador para salvamentos em alturas) e (4) a intervenção propriamente dita. O fim da ocorrência ocorre com o salvamento da vítima e consequente encaminhamento dela aos serviços de saúde, ou quando a intervenção não tem o resultado esperado em face de concretização do ato pela vítima, resultando no óbito da vítima ou em lesões consideradas graves.

A execução desse trabalho ocorre mediante a existência de prescrições, devido sua natureza o trabalhador contribui significativamente com sua experiência, inteligência e maneira de trabalhar com a finalidade de preencher o espaço entre aquilo que é prescrito e o real. Frequentemente o trabalhador corrige falhas para suprimir a possibilidade de acidentes, o que repercute nas vivências de prazer e sofrimento o que evidencia ser um trabalho marcado pelo protagonismo das relações humanas. Assim, relações com a hierarquia, entre trabalhadores e com a sociedade são exacerbadas e determinantes nas vivências dos trabalhadores, trazendo maior distanciamento entre aquilo que é prescrito para o real do trabalho (MEDEIROS; MENDES, 2013; DEJOURS, 2000).

Neste trabalho de intervenção os trabalhadores lidam com a ambivalência do sentimento de realização e orgulho pela execução do trabalho, ao mesmo tempo em que consideram sua profissão estressante e perigosa, pois colocam em risco suas vidas para salvar a vida de outras pessoas e convivem com a pressão, por excelência, em que a menor falha pode ocasionar a perda de sua vida, de seus companheiros de trabalho, ou de quem se destina salvar (NATIVIDADE, 2009). Portanto, convivem na intervenção à tentativa de suicídio com a ambivalência de se dispor a salvar vida de quem momentaneamente decidiu não querer viver. Quando o ato se concretiza os trabalhadores lidam com a marca da impossibilidade de entender os motivos que causaram tal fato, pois apesar da pretensão de decifrar estes motivos não há como os mesmos serem decifrados com a morte do sujeito e, consequentemente, a impossibilidade de interpelá-lo (PIPKIN, 2009).

Assim, os trabalhadores que se colocam a intervir experimentam sentimentos tendenciosos de afastamento. Na consideração de atendimento por equipe de saúde a sujeitos em risco de suicídio constatou-se em alguns casos o desenvolvimento de sentimento de impotência, raiva, ausência de empatia e desesperança. Esses sentimentos são vivenciados em virtude de que o estigma e tabu que envolvem o tema passa a ser acentuado, devido a visão de serem lesões ou mortes autoprovocadas e, consequentemente, possíveis de serem 
prevenidas. O profissional questiona-se, mesmo que inconscientemente, o motivo do suicida não ser punido e sim contemplado por assistência (HOLDSWORTH; BELSHAW; MURRAY, 2001; MELEIRO; BOTEGA; PRATES, 2004).

Além disso, as crenças acerca do ato suicida presentes no contexto social, por vezes, também se manifestam em profissionais, principalmente se carece a eles devida formação e informação quanto ao fenômeno. Meleiro, Botega, Prates (2004) apontam as principais crenças equivocadas que permeiam o ideário de profissionais responsáveis pelo atendimento de vítima de suicídio, destacando que nesse ideário estabelecer conversa sobre suicídio pode induzir ao ato, e que a ameaça ao suicídio representa apenas manipulação, pois quem pretende se matar não se expressa por meio de ameaça e de fato se mata. Assim, quem se mata seria diferente daqueles que apenas tentam. Não obstante aqueles considerados sobreviventes sentem-se na necessidade de se assegurar de que não serão vítimas das mesmas circunstâncias. Existe grande preocupação “[...] em relação a serem engolfados pelas mesmas tendências autodestrutivas presentes no morto [...]" (SILVA, 2009. p. 130).

Para tanto, diante da iminência do trabalho de intervenção em crises suicidas repercutem em vivências aos trabalhadores, a seguir será apresentado a metodologia utilizada no processo de pesquisa.

\section{METODOLOGIA}

Motivado pela apropriação de ideias e conceitos oriundos da Psicodinâmica do Trabalho, a qual preconiza serem o sofrimento e o prazer dados essencialmente subjetivos, torna-se ilusório qualquer tentativa de objetivá-los (DEJOURS, 2011c). Assim, utilizou-se para o desenvolvimento desse artigo a abordagem qualitativa. Para essa abordagem os fenômenos e a forma de interpretação são únicos, sendo o processo mais importante que os resultados, não havendo busca por verdade única, causalidade ou generalizações (TRIVIÑOS, 1987).

A produção dos dados ocorreu mediante entrevista semiestruturada tendo sido interpelados 15 (quinze) trabalhadores de uma mesma organização de trabalho que já haviam atuado em intervenção em crises suicidas. Em razão de aspectos éticos ${ }^{4}$ a organização de trabalho pesquisada não será identificada, bem como os trabalhadores entrevistados que serão

\footnotetext{
${ }^{4}$ A realização dessa pesquisa aconteceu mediante observação dos trâmites éticos descritos na Resolução ${ }^{0} 510$ de 2016, que delineia princípios éticos das pesquisas em ciências sociais quando envolvem dados produzidos diretamente com os participantes (BRASIL, 2016). O projeto de pesquisa foi submetido e aprovado pelo Comitê de Ética e Pesquisa (CAAE 66277917.1.0000.5542).
}

REAd | Porto Alegre - Vol. 24 - No 2 - Maio / Agosto 2018 - p. 106-134 
nomeados nesse artigo como TRAB 001 a TRAB 015. A escolha da entrevista semiestruturada é justificada devido a centralidade dada a fala em investigações com uso da Psicodinâmica do Trabalho, como meio de subjetivação do sofrimento e do prazer: o sofrimento e o prazer não são visíveis e mensuráveis, só se faz possível acessá-los através da fala no momento em que o sujeito nomeia o que sente. Por meio do manejo desta técnica é possível intervir para que dizeres sejam feitos e encarnados com intensidade em seus conteúdos de eventos e afetos (MENDES; ARAÚJO, 2011; TEDESCO; SADE; CALIMAN, 2013). Os trabalhadores pesquisados possuíam a época das entrevistas idades entre 27 (vinte e sete) e 49 (quarenta e nove) anos, tempo de trabalho na organização laboral entre 5 (cinco) e 28 (vinte e oito) anos. Dois deles se identificaram como gênero feminino e os demais com o gênero masculino. Quanto à formação, apenas um participante se identificou cursando ensino superior, um formado no ensino técnico e os demais detentores de diploma de nível superior.

A realização da entrevista ocorreu mediante a inserção do pesquisador em campo, ou seja, mediante a presença na sede da organização de trabalho em dias alternados (a produção de dados ocorreu no lapso temporal de quatro meses). Primeiramente realizou-se contato com os trabalhadores a fim de esclarecer os objetivos da pesquisa, riscos e possibilidades de desconfortos. Esse processo de inserção em campo aconteceu após a divulgação da realização da pesquisa via intranet da instituição em que eram delineados objetivos e procedimentos da produção de dados. Aqueles voluntariamente interessados a participar, após a verificação de terem atuado em intervenção de crises suicidas, eram interpelados.

Após a produção de dados as entrevistas foram transcritas e analisadas sob a ótica da Psicodinâmica do Trabalho por meio da análise de conteúdo, compreendida como um conjunto de técnicas que visa analisar as comunicações através da sistematização de procedimentos objetivos, permitindo a inferência de conhecimentos relativos às mensagens (BARDIN, 2009). Esta análise, conforme Figura 1 abaixo, compreendeu a análise dos dados produzidos em categorias apriorísticas determinada mediante o objetivo de pesquisa: vivências de prazer e vivências de sofrimento. Após esse processo, foi realizada subcategorização mediante conceitos da Psicodinâmica do Trabalho, surgindo então as seguintes subcategorias relacionadas às: (1) vivências de prazer: estabilidade e identificação com a atividade; reconhecimento em seu sentido de constatação e de gratidão (DEJOURS, 2011a) e espaços de expressão do trabalhador, bem como subcategorias relacionadas às (2) vivências de sofrimento que baseiam-se no risco ser a própria pessoa (intencionalidade), originando as vivências do não êxito, do risco vivenciado pelos trabalhadores, a 
imprevisibilidade da evolução da ocorrência e o fato da intervenção não ser unicamente física.

Figura 1 - Análise de dados: Categorias e Subcategorias

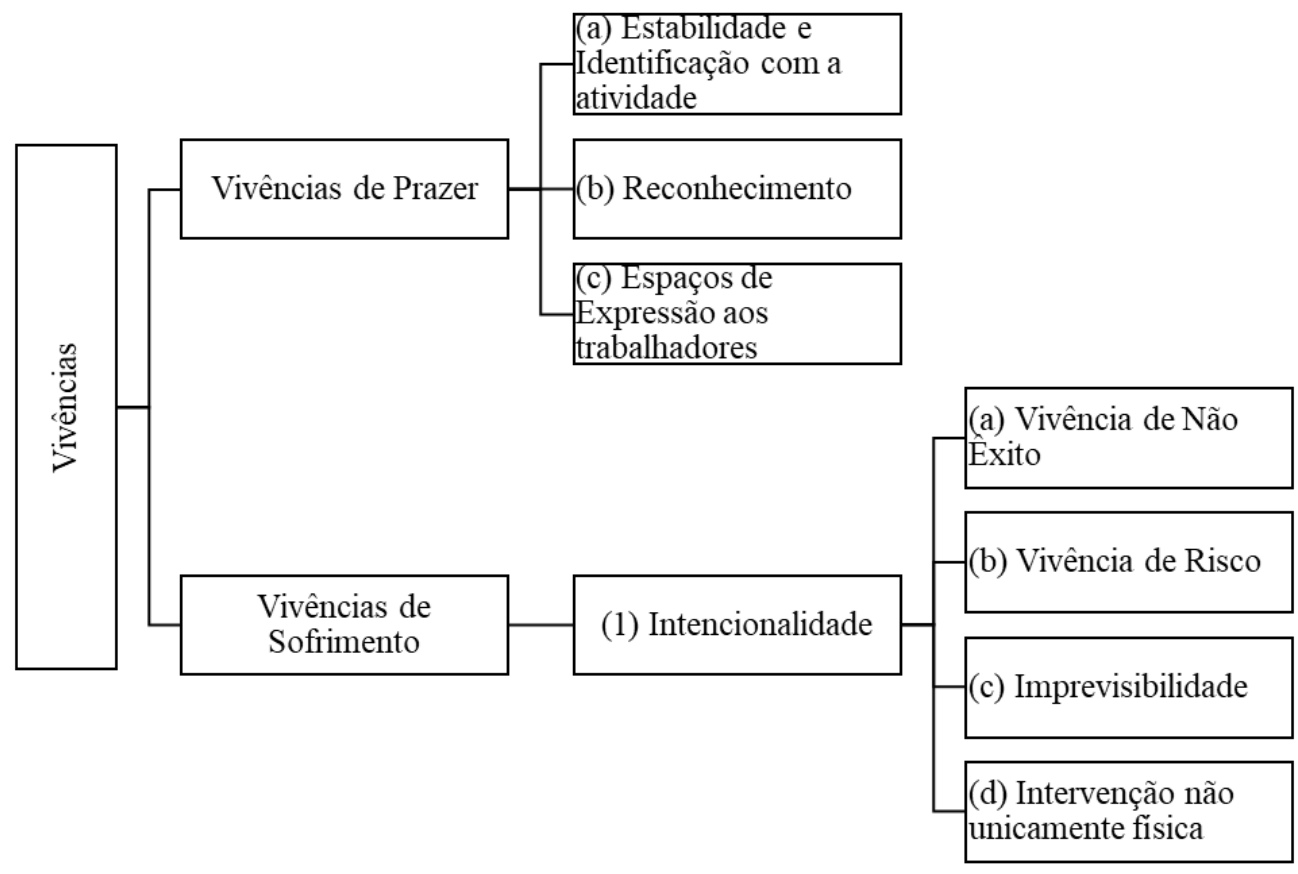

Fonte: elaborada pelos autores.

Assim, mediante a observância de tais aspectos metodológicos, atingiram-se os resultados apresentados a seguir.

\section{RESULTADOS E DISCUSSÕES}

Atendendo ao objetivo deste artigo que busca compreender as vivências de prazer e sofrimento de trabalhadores face o trabalho de intervenção em crises suicidas, a análise dos dados produzidos está organizada em duas categorias principais: 1) vivências de prazer e 2) vivências de sofrimento. Estas categorias são abordadas a seguir iniciando-se este debate com a análise das vivências de prazer para posteriormente se analisar as vivências de sofrimento dos trabalhadores. Os resultados reafirmam a compreensão de serem as vivências de prazer e sofrimento experimentadas pelos trabalhadores de maneira simultânea, não se anulando entre si, ao ponto que o trabalhador avalia seu contexto de trabalho como impróprio, mas que também possui fontes de prazer (MAISSIAT; LAUTERT; PAI; TAVARES, 2015). 


\subsection{VIVÊNCIAS DE PRAZER: É GRATIFICANTE}

As vivências de prazer são constatadas em níveis variáveis entre os sujeitos em razão do sentido da atividade para o trabalhador estar associado à sua história de vida, trazendo aspectos singulares a vivência de prazer, assim como de sofrimento (MENDES, 1995). A primeira categoria de análise - (a) estabilidade e identificação com a atividade - se manifesta primeiramente associada ao processo de ingresso na organização, mediante ao processo singular de busca de satisfação, realização e identificação presentes neste evento. Entretanto, estes sentidos surgem nos enunciados dos trabalhadores de forma anacrônica, sendo simultâneos e não excludentes entre si. São constantes os comentários que mesclam a busca por uma satisfação mediante a identificação com a atividade, simultâneo a busca por estabilidade:

[...] quando eu entrei eu trabalhava no escritório de engenharia, e teve uma crise na construção civil, logo que eu saí apareceu propaganda na televisão para concurso e eu fui. Mas teve uma coisa que me marcou, eu era adolescente ainda, eu estava na praia e teve uma pessoa afogada, ai eu vi o pessoal [...] quando chegou, com tudo ali junto, então aquilo me chamou muito atenção (TRAB. 001).

A primeira razão para o ingresso na organização é motivada pelo fato de aprovação em concurso público representar estabilidade, significando ao trabalhador esperança de ascensão e progresso social. Por outro lado, existe uma rede de significados que não se resume ao fato de o ingresso na organização representar superação a um processo de crise, pois coexistem eventos nas histórias de vida dos trabalhadores com a própria organização, ou ainda uma grande aproximação à natureza do trabalho. Assim, surge a identificação com a atividade executada, representando vivência de prazer proporcionada devido às diversas dimensões do trabalho que exercem uma função psíquica e atuam como alicerce da constituição do sujeito e de sua rede de significados (LANCMAN, 2011). É a singularidade da história relatada em consonância com a organização de trabalho que conduz a vivência de prazer. Na possibilidade contrária, havendo conflito entre sua história e a organização de trabalho, existiria a vivência de sofrimento (DEJOURS, 2000). Essa consonância se desvela na construção do comentário quando o ingresso na organização deixa de ser um fato ficto e se concretiza, conforme declarado abaixo:

[...] Quando consegui entrar [...], nossa que era tudo, tudo, tudo, tudo, tudo, tudo. Eu não sabia, do meu ponto de vista, é interessante 
dizer que havia uma coisa que eu não sabia o que era, rígida hierarquia, eu não sabia que fazia parte da organização [...]. Isso foi um período de adaptação para mim [...]. Mas depois você acostuma, você veste o uniforme e pronto, você aceitou aquilo e acabou (TRAB. 002).

A busca pela vivência de prazer em razão de uma história individual detentora de projetos de esperanças e desejos conflita com a organização de trabalho que por vezes ignora esses desejos, suprimindo a vivência de prazer (DEJOURS, 2000). Entretanto o processo de aceitação ocorre mediante a uma negociação social do mundo (subjetivo) com a organização de trabalho (social), à medida que se realiza com a atividade, mas ao mesmo tempo aceita vestir o uniforme e aceitar "aquilo" (MENDES, 1995). É um processo simultâneo de prazer e sofrimento que não necessariamente se anulam entre si: à medida que a organização de trabalho sucumbiu com o ideário de realização, a execução da atividade permanece sendo fonte de identificação e prazer. Espera-se do trabalho um espaço privilegiado de trocas entre o mundo interno e externo do trabalhador, sendo mediador central de desenvolvimento, aquisição e complementação de identidade pessoal, determinando inclusive a qualidade e constituição da vida psíquica do trabalhador (LANCMAN, 2011).

A caracterização da organização pesquisada com a missão de salvar vidas e ajuda ao próximo, manifestadas pelos trabalhadores, aproxima o trabalhador que busca no trabalho algum nível de identificação e correspondência entre seus valores e a organização. É a existência de identificação com a atividade e com os valores da organização que surge o prazer, conforme enunciados a seguir: "[...] eu também sou cristão. Eu também sinto necessidade de fazer alguma coisa pelo próximo de alguma forma" (TRAB. 003); "É realmente poder ajudar as pessoas era o que representava para mim, era ser útil a comunidade mesmo" (TRAB. 004). Estes enunciados manifestam a expectativa do trabalho ser uma via de aquisição de identidade pessoal, determinando inclusive qualidade de vida e construto de valores sociais e culturais (DAL ROSSO, 2008).

Constata-se o encontro do trabalhador que almeja ajudar e ser útil a sociedade com a organização que fomenta essa ajuda. É a consolidação de correspondências de valores, traduzidos em espaços de expressão dos sujeitos, que os remete em vivências de prazer. Não se trata de harmonia entre trabalhador e organização, e sim sua inscrição em um espaço de luta, havendo tentativa da organização do trabalho de dominar e limitar o quanto possível, ou o quanto necessário este espaço. Além disso, esse encontro de valores induz ao engajamento do trabalhador e a celebração de um contrato moral junto à organização, podendo ser sua 
ruptura com efeitos dramáticos relacionados a sua identidade (DEJOURS, 2011d; DEJOURS; BÈGUE, 2010).

Em contrapartida, se a correspondência de valores permite à existência de um contrato moral, os mesmos valores de ajudar o próximo, ser útil à sociedade e contribuir de forma incisiva, estes valores também denotam uma significativa vivência de prazer aos trabalhadores em busca de (b) reconhecimento, segunda categoria de análise. $\mathrm{O}$ reconhecimento se concretiza aos trabalhadores como vivência de prazer mediante um julgamento qualitativo de constatação e de utilidade de suas atividades, sendo algo individualizado e vivenciado pelo trabalhador quando sua atividade o faz se sentir socialmente útil (DEJOURS, 2011c). Também se concretiza o reconhecimento no sentido de gratidão (DEJOURS, 2011a), estando essa premissa mais presente no coletivo de trabalho, consolidado através do julgamento do outro, nesse caso a sociedade: “[...] em qualquer lugar que chegava é bem recebido. Até em locais de dificil acesso [...] a gente é muito bem recebido" (TRAB. 005).

Essa premissa do reconhecimento é vivenciada de duas maneiras: (1) o reconhecimento da organização e (2) o reconhecimento do resultado do trabalho. O reconhecimento social da organização do trabalho motivado pela natureza da atividade executada (salvar vidas) faz com que seja vivenciado prazer por compor a organização, pois a organização ser socialmente reconhecida é sinônimo dos trabalhadores que a compõe também serem. Já o reconhecimento do resultado do trabalho se consolida quando o trabalhador se coloca a atuar e em razão do resultado desta atuação ser reconhecido. Neste caso, o reconhecimento não é relativo à pessoa do trabalhador, mas sobre o resultado satisfatório de seu trabalho, sendo que apenas em um segundo momento que esse trabalhador se beneficiará desses julgamentos de reconhecimento (DEJOURS; BÈGUE, 2010). Essa ambiguidade se fortalece quando quem reconhece, mesmo que em razão de um trabalho satisfatório, nomeia o trabalhador de herói e não a qualidade do trabalho alcançado. Vale ressaltar que não há uma separação cartesiana entre trabalho e trabalhador. Desta maneira, se concretiza de forma ambígua o reconhecimento do trabalhador e o reconhecimento da organização, não se distinguindo um do outro, pois são identidades que em certo aspecto se fundem. Essa fusão é corroborada pelos controles de conduta realizados pela própria organização, abrangendo inclusive a vida dos trabalhadores para além do espaço da organização:

As pessoas sempre associam, tanto é que tem um controle de comportamento que a gente tem que ter pela corregedoria nossa, para que as pessoas sempre têm uma boa imagem do profissional. Se 
eu falo que sou [...] e fico fazendo alguma coisa errada e isso não está condizente com a minha profissão (TRAB. 006).

A atividade laboral assume função central na ação de sociabilidade do trabalhador, movendo e sendo intermediador de relações e sensações, em que o trabalhador coloca a sua subjetividade, constituindo a intersubjetividade no trabalho. Essa dinâmica é definida pela atuação de forças visíveis e invisíveis, objetivas e subjetivas, psíquicas e sociais, políticas e econômicas, vividas e sentidas, mas não visíveis no olhar de quem reconhece (ALVES, 2011; CARMO; GUIMARÃES; CAEIRO, 2016). Independentemente de o reconhecimento experimentado ser originado de duas vertentes, ambos fortalecem a identidade dos trabalhadores, transformando vivências de sofrimento em prazer (DEJOURS; BÈGUE, 2010). Não significa dizer que as contribuições para o fortalecimento da identidade dos sujeitos ocorram de forma linear ou idêntica nas duas maneiras de reconhecimento, uma vez que no nível das sensações o reconhecimento pelo resultado do trabalho é percebido com maior intensidade.

Para tanto, o lograr êxito, expressão utilizada pelos trabalhadores no sentido de alcançar o resultado almejado em determinada intervenção em crise suicida, resulta como vivência de prazer sentida pelos trabalhadores com maior intensidade de forma pontual e que, com o passar do tempo a intensidade diminui, mas não se extingui, estando presente na memória do trabalhadores, em alguns casos, na memória da organização. A pontualidade dessa sensação é resultado de o reconhecimento ser imediatamente após a lograr êxito, ao mesmo tempo de não ser em todas as situações de êxito que o reconhecimento do outro (sociedade) acontece, se concretiza ou se é sentido. A concretização e a pontualidade desse reconhecimento são percebidas através de comentários como: “[...] Quando tem um atendimento também que você vê a população, às vezes a resposta é imediata, você sai daí às vezes tratado como herói [...]" (TRAB. 001).

As expressões dessas vivências se concretizam com muito mais vivacidade ao se comparar com o reconhecimento enquanto organização. Além disso, há maior intensidade na construção desses comentários quando tais são constantemente acompanhados de expressões como: "é gratificante" (TRAB 002), "é essa questão da gratificação mesmo”, "a gente sai bem feliz” (TRAB 005), “muito boa” (TRAB 015) e “muito satisfatório" (TRAB 013).

Todavia, a vivência de prazer em face desse reconhecimento também perfaz espaço de luta, pois sua vivência é questionada especialmente por aqueles trabalhadores que vivenciam de alguma forma a quebra de um pacto moral entre si e a organização. Geralmente o trabalhador que descreve vivenciar injustiças no contexto do trabalho afirma ser esse 
reconhecimento significativo "aos meninos de 20 anos que chegaram agora" (TRAB. 012). De modo análogo, o trabalhador que relata problemas na gestão descreve a vivência de "uma lua de mel" (TRAB.013) logo no início de sua entrada na organização, face ao reconhecimento, mas que agora em razão de problemáticas vivenciadas esse sentimento está em segundo plano.

O reconhecimento depende do sentido do sofrimento vivenciado. Se o trabalho é reconhecido, os esforços, as angústias, dúvidas, decepções e desânimo são percebidos como se não tivessem sido em vão. Quando o trabalhador não experimenta níveis de reconhecimento persistem as vivências de sofrimento em um círculo vicioso capaz de desestabilizar a identidade e a personalidade, conduzindo à doença mental (DEJOURS, 2011a). Nesse sentido, o mesmo trabalhador que relata problemas com a gestão e, consequentemente deixa o reconhecimento em segundo plano, relata diagnóstico de doença mental, que em seu ponto de vista está associado à forma como o trabalho se organiza:

Sobre a questão da gestão rígida, nessas situações ai de poder, isso me fez, igual eu estava falando que estava no psicólogo, eu adoeci no final do ano passado fui diagnosticado com depressão, com crise de ansiedade. Tenho feito tratamento, isso dai é a forma que me influenciou em minha vida pessoal, que por mais que você se esforce em ser um profissional esforçado comprometido com o serviço tem um lado humano que acaba ficando cada vez mais de lado, adoecendo até o momento que você precisa pegar tratar e tentar se reerguer, se colocar no seu devido lugar que antes estava sub julgado (Comentário não será identificado).

Mesmo o trabalhador colocando as vivências em uma linha temporal, destaca-se a existência de um ciclo vicioso, no qual não é possível demarcar a linearidade dos fatos. Inexiste neutralidade do trabalho diante da saúde mental, sendo que o reconhecimento não é uma reinvindicação secundária, pelo contrário, é decisivo na mobilização do trabalhador e em sua motivação (DEJOURS, 2011a). O trabalhador inscrito em um espaço de resistência ou em razão do adoecimento devido as falhas no processo de resistência, vivencia outra luta que leva ao prazer: (c) os espaços de expressão do trabalhador (terceira categoria de análise, conforme Figura 1), traduzido como "esforço, comprometimento", em uma organização de rígida burocracia.

Assim, uma vez que a organização de trabalho é vista como "engessada e opressora em certas coisas" (TRAB. 007), os espaços de expressão do trabalhador são tênues vivências 
de prazer em resistência constante as vivências de sofrimento. Esta expressão se configura nos espaços que surgem entre o prescrito e o real. Estes espaços são estabelecidos em virtude do trabalho não ser inteiramente transparente, inteligível, reproduzível e formalizável. Contrariamente, o trabalho de intervenção em crises suicidas se configura como a criação do novo, exigindo iniciativa, inventividade, criatividade e emprego de inteligência, criando espaços para o trabalhador se expressar (DEJOURS, 2007, 2011a).

Assim a variabilidade e a imprevisibilidade das intervenções em crises suicidas, uma vez não totalmente absorvidas pela organização prescrita do trabalho, deixa a cargo do trabalhador a expressão de si para que a atividade se realize: “[...] a gente tem um procedimento operacional padrão, mas nunca na ocorrência você vai chegar e ter esse procedimento certinho, por que não tem como, você tem que analisar a cena [...]" (TRAB. 004). Essa realidade desconstrói a indignidade operária existente nas situações em que o trabalhador é considerado um apêndice de máquina, sendo que nas intervenções em crises suicidas ocorre justamente o contrário, pois devido a singularidade e especificidade de cada intervenção, não há como se ter completa prescrição do trabalho, requerendo que o trabalhador seja imaginativo, inteligente e atue de forma personificada (DEJOURS, 2007). É indubitável que essa expressão do trabalhador, a compreensão de um trabalho essencialmente humano, se unifica com a vivência de prazer no reconhecimento de utilidade do que se faz, do reconhecimento do outro e da própria identificação com a atividade.

Contudo, a vivência de prazer proporcionada pela impossibilidade de prescrição e a não total absorção do real pela organização, também se consolida como vivência de sofrimento. Nesse sentido é necessário ressaltar que no processo de compreensão das vivências existe o sentido de separação entre prazer e sofrimento, estas vivências sempre coexistem em linha tênue constantemente transpassada e vivenciada em espaços de resistência e luta.

\subsection{VIVÊNCIAS DE SOFRIMENTO: "O RISCO É A PRÓPRIA PESSOA”}

As vivências de sofrimento experienciadas na intervenção em crises suicidas se consolidam na percepção pelos trabalhadores de nuances singulares a essas vítimas, relacionadas ao desespero humano, a dialética entre vida e morte e com o fato de serem as vítimas sujeitos que morreram existencialmente e não expressaram prazer em estarem vivos. Dessa maneira se configuram como propulsores de vivências de sofrimento o fato de o risco ser a própria pessoa, ou seja, concretizado na intencionalidade e nos atos da própria vítima 
(MELEIRO; BAHLS, 2004). Nesse sentido, emergiram com os enunciados dos trabalhadores as seguintes categorias de vivências de sofrimento no trabalho relacionadas a (1) intencionalidade da vítima: (a) a vivência de não êxito; (b) vivência de risco; (c) vivência de imprevisibilidade; e (d) o fato de não ser uma intervenção tão somente física. Estas categorias serão analisadas a seguir.

A (1) intencionalidade da vítima existente nas crises suicidas denota aos trabalhadores que o "problema a ser resolvido" (TRAB. 007) é o próprio comportamento da vítima, refletindo como vivência de sofrimento aos trabalhadores à medida que nas demais intervenções de responsabilidade dos trabalhadores a vítima querer essencialmente viver, tendo, portanto, comportamento colaborativo. Assim, a fim de compreender tais vivências se terá como ponto de partida de análise a forma como se consolida a ótica da percepção de que o risco está na própria vítima. Sequencialmente busca-se compreender as vivências de sofrimento derivadas desse aspecto. Para tanto, inicia-se com a evidenciação do percebido pelos trabalhadores:

As outras ocorrências o risco está fora da pessoa, nessa não, o risco é a própria pessoa, então ela foge, então a gente fica mais limitado ainda, porque? Por que o risco não é uma árvore cair, árvore eu consigo, o risco é a pessoa cair, pular, então está dentro dela, estou mais limitado. Por isso que falo para você, me afetaria mais, por estar mais limitado, às vezes eu sentiria necessidade de atuar mais, de explorar mais a possibilidade de salvamento daquela pessoa, com certeza ia ficar, isso daí você encontra caso de profissional que ficam bem afetados de que a pessoa pulou "nossa se eu tivesse segurado" (TRAB. 007).

Quando os trabalhadores comparam as ocorrências denota-se a compreensão do próprio conceito de suicídio em que o resultado morte é alcançado mediante ato voluntário praticado pela própria vítima com a intencionalidade de se alcançar este resultado (MELEIRO; BAHLS, 2004). O fato de o risco ser a própria pessoa demarca a intencionalidade da vítima e a prática do ato voluntário. Contrariamente nas "outras ocorrências" o risco está "fora da pessoa" e, essencialmente, a vítima desejar sair da situação de risco adotando um comportamento colaborativo. A vivência de sofrimento se configura à medida que o risco físico, aquele que está fora da pessoa, é mais provável de se gerir do que quando o risco é totalmente humano e intencional. São circunstâncias em que são demandadas a engenhosidade do trabalhador para suprir espaços daquilo que existe como 
prescrito (vivência de prazer). Entretanto, na evidente possibilidade de não êxito e, consequentemente, não reconhecimento, emerge a vivência de sofrimento, que em alguns casos na percepção do trabalhador é de se atribuir como responsável pelo resultado obtido, em uma assunção de responsabilidade: "Você encontra caso de profissional que ficam bem afetados de que a pessoa pulou "nossa se eu tivesse segurado" (TRAB. 007). Trata-se de situações reais de trabalho complexas e polivalentes em que o "sofrimento pode andar lado a lado com o prazer" (DEJOURS, 2011b, p. 189). Neste contexto se consolidam ambivalências nas quais a vítima vivencia o desejo de morte e vida, e o trabalhador busca impedir o ato e mantê-la viva (FREITAS; BORGES, 2014).

A percepção de que o risco está na pessoa perpassa a compreensão que a cena se altera mediante comportamentos e condutas da vítima, mesmo que esses deixem de ser voluntários e sejam acidentais, por exemplo. Há, portanto, (a) a vivência de não êxito ou ainda da possibilidade de não intervenção exacerbada por uma visão comparativa com outras ocorrências oriundas de uma visão de a princípio a vítima estar fisicamente íntegra e o seu ato ocasionar óbito: "O medo de a questão de fracassar, mesmo nesse sentido assim de a pessoa estar na sua frente e pular" (TRAB. 008).

\section{[...] você tem que levar à força. Então a diferença sim no atendimento} ela não quer ser atendida, a vítima suicida ela não quer que você a leve para o hospital, ela não quer ser atendida por você, porque você está interrompendo a tentativa dela, então é muito diferente sim e às vezes a gente até acha muito empecilho por conta disso (TRAB. 004).

A vivência de não êxito é propulsora de frustração e não reconhecimento pelo "medo de fracassar" (TRAB. 008) e se dá indubitavelmente em razão da intencionalidade da vítima, de seus atos e da possibilidade de intervenção do trabalhador. Parte do fato de o trabalhador estar na contrapartida da intencionalidade, uma vez que almeja essencialmente interromper a tentativa, mas que para isso às vezes tem que "conter a vítima", "amarrar", "levar a vítima a força" (TRAB. 004), circunscrito na perspectiva de a vítima não querer ser atendida. Convive o trabalhador com a possibilidade de a vítima estar à sua frente e pular. Evidentemente se consolidam contrariedades entre a perspectiva do trabalhador de salvar e da vítima de morrer, acentuada para o trabalhador em virtude de almejar através de o salvamento lograr êxito e obter reconhecimento. Não se há outra perspectiva por parte do trabalhador a não ser salvar emergindo a comparação do risco de morte da vítima em circunstâncias distintas do suicídio, pois apesar das facetas de desespero "ela [a vítima] não quis causar aquilo" (TRAB. 004). 
Mesmo que se perceba a intencionalidade da vítima como o principal motivador de se existir a necessidade de intervenção o trabalhador convive com o sofrimento em virtude do medo de erro ou de incompetência. É certo que esse medo se relaciona ao objetivo do trabalho em salvar, por conseguinte, o óbito da vítima significa não atingir o objetivo e assim não há reconhecimento, fazendo com que o trabalho deixe de ser operador de prazer e passa a ser propulsor de sofrimento. Mas, antes desse cenário definitivo a interrupção da tentativa com salvamento ou a morte da vítima, surge o medo manifestado nos questionamentos: se a vítima pular? Se eu não souber conversar? Se a vítima se desequilibrar? Certamente essas expressões de medo explícitas e implícitas nos enunciados surgem em razão da interpelação, já que na execução diária do trabalho esse medo é dissimulado. Nessas situações os trabalhadores são tomados pelo medo da expectativa de serem incompetentes e incapazes de lidar com situações incertas, cuja prescrição completa do trabalho é impossível devido à singularidade que envolve cada atendimento de suicídio, mas que exigem responsabilidade do trabalhador e pela perplexidade de nem sempre se identificar com precisão as próprias falhas, sejam elas do sistema técnico ou provenientes da vítima (desequilíbrio que pode ocasionar a queda, por exemplo), mas que não são impeditivos de se executar o trabalho (DEJOURS, 2000; DEJOURS, 2007).

A consequência do medo da incompetência e das incertezas geradas diante da impossibilidade da plena prescrição do trabalho a ser realizado, compromete a busca pelo resultado final do trabalho que é salvar e, consequentemente, a obtenção de reconhecimento, seja de si, do outro ou da sociedade, conduzindo o trabalhador a atitudes de se colocar em risco.

Porque estava em uma situação de perigo eminente ali, ele podia pular em qualquer momento, e chegando mais à noite, e mais carro e mais gente, a pessoa vai entrando em desespero, se ela quiser, não né, se ela se sentir um pouco mais acuada ela vai pular. Mas a situação ali era o seguinte a gente tinha que se equipar, igual eu falei a gente tinha que estar em segurança. [...] Ele foi sem a segurança, ele foi pegou o cara, ele pulou e trouxe. Eu falei com ele depois, se esse homem se joga para frente você cai lá embaixo. Então assim, tinha tempo para se equipar? (TRAB.008).

Trata-se da (b) vivência do risco também delineada pelo fator intencionalidade da vítima. A opção do trabalhador em priorizar salvar a vítima na contrapartida de não se equipar adequadamente para também não se tornar uma vítima, evidencia a postura de se 
querer atingir o resultado, mesmo que para isso se coloque em risco. Nesse caso o risco é percebido pelo olhar do outro ao expressar a possibilidade da vítima e do profissional caírem juntos. Isto representa uma condição de trabalho que faz sofrer, entretanto, a racionalização corrobora com justificativas socialmente valorizadas para explicar situações desconfortáveis minimizando esta percepção (TSCHIEDEL; MONTEIRO, 2013).

As relações sociais do trabalho desempenham a função de conduzir o trabalhador à ação, mesmo que em risco. Essas relações tornam latente o fato do trabalho estar submetido ao julgamento utilitarista presente no cerne de profissões arriscadas como a posta em análise. Há uma distorção social em que a desobediência (não se equipar) passa a ser vista como ato positivo, pois o trabalhador supera seu medo para salvar a vítima. Quando se experimenta o risco inerente a atividade e obtém o resultado almejado, em virtude da visão utilitarista das relações sociais do trabalho, se concretiza o reconhecimento sentido positivamente pelo trabalhador. Percebe-se um elo estreito entre a vivência de sofrimento com risco e medo, para a vivência de prazer e identificação com a atividade (DEJOURS, 2007).

Não obstante, o fato da intencionalidade e a ocorrência estar delineada face o comportamento da vítima, conduz a (c) vivência da imprevisibilidade na progressão do atendimento, agravado por não ser latente/evidente aos trabalhadores a suficiente existência de prescrição. Nesse sentido, interpelados quanto à existência de prescrição para intervir em crises suicidas não há consenso no coletivo de trabalho quanto existir ou não:

Quando a gente se depara com uma pessoa que é de suicídio a gente fica pensando o que fazer como fazer, e aí a gente começa a ver como a falta de uma prática ou de uma teoria ou de um manual para a gente estudar faz falta ali na hora e ai a gente tem que ter a gente vai pela base prática do que a gente já atendeu anteriormente (TRAB. 009).

[...]. Já o suicida se tem o passo a passo eu não sei. Nunca vi, entendeu?! Lá eu acho que a pessoas fica mais apreensiva por que não tem o passo a passo, é o manual que a gente fala, programa de treinamento. Então é por isso que acho que a gente fica mais apreensivo, na questão de como lidar com ele e como a gente sente, né. Está lidando com a vida, está vivo e vai se jogar (TRAB. 005).

Essa vivência de sofrimento se configura em razão dos trabalhadores serem demandados a suprir aquilo que não é prescrito mediante a expressão de si e emprego de engenhosidade e criatividade. Contudo, a ausência de prescrição não seria a expressão 
sobremaneira do trabalhador constituindo vivências de prazer? Sem sombra de dúvida se desvela uma complexa e polivalente faceta das relações de trabalho, pois no atendimento a suicídio a ausência de prescrição gera sofrimento, ao invés de prazer no trabalho.

A esta compreensão obrigatoriamente se retorna ao conceito de trabalho que, além de ser fazer funcionar o tecido social e as dinâmicas intersubjetivas indispensáveis à psicodinâmica do reconhecimento, é também executar atos técnicos. Há uma reivindicação no trabalho analisado por prescrições que os coordenem, ao mesmo tempo em que os permitam se expressar. Quando a prescrição preconiza trabalho repetitivo em uma produção em série não havendo espaços para empregar a engenhosidade e inteligibilidade do trabalhador, por exemplo, essa ausência de espaços de expressão conduz o trabalhador ao sofrimento. Conquanto na possibilidade inversa, diante dos imprevistos e de possibilidades mínimas, é exacerbada ao trabalhador a percepção de resistência do real (DEJOURS, 2003; 2011c). Por conseguinte, expecta-se na organização do trabalho por um hiato entre prescrito e real que seja tolerante, oferecendo margens a engenhosidade, inteligibilidade e criatividade do trabalhador, mas também capaz de regular erros, fraudes e desobediência (DESSORS; SCHRAM, 1992). Em suma, o trabalhador ao intervir em crises suicidas reivindica prescrições suficientemente norteadoras, sofrendo diante dos imprevistos e resistências do real (DEJOURS, 2011c).

Para essa compreensão, destaca-se o fato dos trabalhadores atuarem com mais frequência em intervenções que demandam mais atuação técnica, com abordagens físicas do que abordagens que sejam imprescindíveis estabelecer diálogo e/ou qualquer outro tipo de relação com a vítima, como ocorre nas intervenções em crises suicidas em que a escuta e empatia para com a vítima são condições importantes para o salvamento. Contudo, como os mesmos trabalhadores atendem uma quantidade maior de ocorrências que não envolvem suicídio isso permite a consolidação de um saber-fazer aos trabalhadores norteados por manuais e prescrições com maior detalhamento que reduzem a percepção de risco, sendo estas prescrições consideradas como facilitadores do trabalho (BARROS; HONÓRIO, 2015; DEJOURS, 2011a).

É preciso considerar o costume e o tempo de trabalho na organização, somados a quantidade de ocorrências atendidas, e a estabilidade de pessoal como favorecedores de desenvolvimento de uma espécie de tradição estabelecida que afasta a angústia e a ansiedade no trabalho. Uma vez que ocorrências de suicídio nem sempre são vistas com uma quantidade expressiva, esse fator deixa de operar (DEJOURS, 2000). 
Devido à quantidade menor de ocorrências de suicídio, os trabalhadores não estão habituados a trabalhar com negociação, surgindo a vivência de sofrimento de nas crises suicidas não (d) serem intervenções unicamente físicas:

Eu tentava tirar o foco dele do problema, eu particularmente prefiro, por doutrina atualmente se prioriza a negociação, eu não gosto muito da negociação, eu sempre preferir entre aspas dar o bote, eu sempre preferi o bote (TRAB. 003).

Agora em uma tentativa de suicídio já é algo mais complexo, que a gente não sabe com o que a gente vai se deparar, se a vítima tem mais refém se a vítima fez ali outras vítimas, a gente não sabe se a vítima está armada, se a vítima está sob uso de álcool drogas medicação, se a vítima tem problema psiquiátrico se não tem, então é uma ocorrência muito mais complexa do que as rotineiras (TRAB. 009).

Os trabalhadores percebem existir maiores variabilidades a serem geridas na intervenção de crises suicidas, vivenciando serem as "mais pesadas em lidar". Sem dúvida a apreensão e o sentir pesado se relacionam ao fato da vítima suicida trazer para mais perto do trabalhador a morte, na contrapartida de uma luta pela vida. A negociação nessas crises não é um simples negociar mediante perguntas e respostas, sendo preciso estabelecer relação de confiança entre vítima e trabalhador de maneira empática e com respeito à história de vida daquele que se pretende salvar (BOTEGA, 2015). Essas nuances tornam a intervenção em crises suicidas mais complexas e conduzem a expressão dos trabalhadores em almejar por abordagens físicas uma vez que nessa forma de atuar há consolidado um saber-fazer na organização de trabalho.

Todavia, mesmo na existência dessas expressões, é evidente para os trabalhadores a necessidade de que as abordagens sejam mediante ao estabelecimento de relações. Não incomum existir expressões que denotem a importância dessa relação, tal como "abordagem física é cem por cento, certo que a pessoa irá fazer de novo" (TRAB. 010), "é necessário criar empatia com a pessoa, é tentar entender o que está acontecendo, é você não recriminar" (TRAB. 011), "você tem que se importar, se você não se importar, você talvez não crie vínculo nenhum" (TRAB. 008). São expressões reveladoras de que mesmo em um cenário adverso de vítimas não colaborativas (querem morrer) e da possibilidade da iminência de defesas psicológicas com a finalidade de não perceber o drama humano condutor de preconceitos, crenças e repulsa, estão os trabalhadores na contrapartida, 
expressando o quão primordial é o estabelecimento da relação no atendimento (BOTEGA, 2015), demonstrando as particularidades do trabalho em situações adversas em cenários de serviços de urgência e profissionais de saúde com atitudes de agressividade, repulsa e resistência (CREPALDI, 2012; SRIVASTAVA; TIWARI, 2012).

\section{CONSIDERAÇÕES FINAIS}

A compreensão à luz da Psicodinâmica do Trabalho de vivências de prazer e sofrimento em face de intervenção em crises suicidas evidenciou-se a complexidade das crises, sendo constantemente demarcada a consolidação de relações humanas, a influência de suas variabilidades no trabalho e nas próprias vivências de sofrimento e prazer. Evidencia que trabalhar não envolve apenas a mobilização do corpo, mas também da inteligência e dos afetos com o poder de operar processo mutatório no sujeito e uma permanente recriação subjetiva concomitantemente geradora de sofrimento e prazer (ARAÚJO; SOUZA, 2015; DEJOURS, 2011b).

Neste processo o intervir em crises suicidas representa uma linha tênue entre as vivências de sofrimento e prazer. Se há possibilidade de prazer nos espaços de expressão ao trabalhador a acentuação da demanda por gerenciar variabilidades pelos trabalhadores nesse mesmo espaço torna latente a vivência de sofrimento, trazendo sentidos de risco, acentuação de imprevisibilidade e torna menos eficazes saberes consolidados ao coletivo de trabalho. Nessa tênue linha a reinvindicação dos trabalhadores é por uma organização de trabalho tolerante, permitindo emprego de engenhosidade ao mesmo tempo em que norteia minimamente a atividade, através de prescrições, diminuindo a sensação de riscos e imprevistos. Contudo, na intervenção em crises suicidas a posição de lidar com a resistência do real é exacerbada com as características da vítima, sendo a tênue linha entre sofrimento e prazer ultrapassada constantemente. Evidentemente em virtude da complexidade da crise suicida inerente ao comportamento de um sujeito em conflito que demarca todo o processo de atendimento, o intervir em crises de suicídio enquanto organização de trabalho coloca os trabalhadores constantemente entre prazer e sofrimento.

Com isso, sugere-se às organizações de trabalho em condições análogas fomentar espaços de expressão aos trabalhadores, como espaços de discussões, para que assim se delineie, a partir das vivências de trabalho, prescrições a fim de se constituir tolerante organização de trabalho. Prescrições que norteiem satisfatoriamente, mas que também permitam e tornem possível o emprego da inteligibilidade e da engenhosidade. Do mesmo 
modo, sugere-se para pesquisas futuras debruçar-se sobre consequências da variabilidade do trabalho e do estabelecimento de relações em virtude desse trabalho, principalmente as atividades que envolvem questões relacionadas a vida e a morte.

\section{REFERENCIAS}

ALDERSON, M. La psychodynamique du travail: objet, considérationsépistémologiques, concepts et prémissesthéoriques. Santé Mentale, v. 29, n. 1, p. 243-260, 2004.

ALVES, G. Trabalho e subjetividade. São Paulo: Boitempo, 2011.

ANTLOGA, C. S.; MENDES, A. M.; MAIA, M. Pleasure and Suffering at Work: Case Study with Employees at the Administrative Section of a Construction Material Company in DF. International Journal of Applied Psychology, v. 2, n. 5, p. 110-118, 2012.

ARAÚJO, A. J. S.; SOUZA, P. C. Z. Resenha: sobre a dinâmica relação entre trabalho e a psique. Organizações e Trabalho, Brasília, v. 15, n. 3, p. 332-334, 2015.

BARDIN, L. Análise de Conteúdo. Lisboa: Edições 70, 2009.

BARROS, N. M. G. C; HONÓRIO, L. C. Riscos de adoecimento no trabalho de médicos e enfermeiros em um hospital regional Mato-Grossense. Rege, v. 22, n. 1, p. 21-39, 2015. BENDASSOLLI, P. F.; SOBOLL, L. A. P. Clínicas do trabalho: filiações, premissas e desafios. Cadernos de Psicologia Social do Trabalho, v. 14, n. 1, p. 59-72, 2011.

BERTOLOTE, J. M.; MELLO-SANTOS, C.; BOTEGA, N. J. Detecção do risco de suicídio nos serviços de emergência psiquiatrica. Revista Brasileira de Psiquiatria, v. 32, Supl. 2, p. $87-95,2010$.

BOTEGA, N. J. Crise Suicida: avaliação e manejo. Porto Alegre: Artmed, 2015.

BRASIL. Resolução n 510 , de 07 de abril de 2016. Dispõe sobre as normas aplicáveis a pesquisas em Ciências Humanas e Sociais. Conselho Nacional de Saúde, Brasília, 07 de abril de 2016. Disponível em: http://conselho.saude.gov.br/resolucoes/2016/Reso510.pdf. Acesso em: 03 nov. 2016.

CARMO, J. G. M.; GUIMARÃES, L. V. M.; CAEIRO, M. L. Prazer e sofrimento no trabalho: vivências de mulheres soldados da PMMG. Farol, v. 3, n. 6, p. 1278-1322, 2016.

CASTEL, R. As metamorfoses da questão social: uma crônica do salário. Petrópolis: Vozes, 1998.

COIMBRA, P. A. M. O gerenciamento de crises policiais em ocorrências envolvendo tentativas de suicídio - uma definição de papéis. Preleção, v. 10, n. 5, p. 57-76, 2011. 
CREPALDI, M. A. Prefácio. In: MALISKA, M. E.; WALLAUER, A. (Orgs.). Suicídio: um desafio para profissionais de saúde. Florianópolis: Pandion, 2012.

DASHTIPOUR, P.; VIDAILLET, B. Work as affective experience: the contribution of Christophe Dejours psychodynamics of work. Organization Studies, v. 24, n. 1, p. 18-35, 2017.

DEJOURS, C. Uma resposta durante o seminário: sofrimento e prazer no trabalho. In: LACMAN, S.; SZNELWAR, L. (Org.). Christophe Dejours: da psicopatologia à psicodinâmica do trabalho. Brasília: Paralelo 15, Rio de Janeiro: Fiocruz, 2011b. p. 185-192. DEJOURS, C. A banalização da injustiça social. Tradução de Luiz A. Monjardim. Reimpressão. Rio de Janeiro: FGV, 2007.

DEJOURS, C. A carga psíquica do trabalho. In: BETIOL, M. I. S. (Org.). Psicodinâmica do Trabalho: contribuições da Escola Dejouriana à análise da relação prazer, sofrimento e trabalho. São Paulo: Atlas, 1994. p. 21-32.

DEJOURS, C. A Loucura do Trabalho: Estudo de Psicopatologia do Trabalho. 5. ed. São Paulo: Cortez, 2000.

DEJOURS, C. A metodologia em psicodinâmica do trabalho. In: LACMAN, S.;

SZNELWAR, L. (Orgs.). Christophe Dejours: da psicopatologia à psicodinâmica do trabalho. Brasília: Paralelo 15, Rio de Janeiro: Fiocruz, 2011c. p. 125-150.

DEJOURS, C. A saúde mental entre impulsos individuais e requisitos coletivos (sublimação e trabalho). In: LACMAN, S.; SZNELWAR, L. (Orgs.). Christophe Dejours: da psicopatologia à psicodinâmica do trabalho. Brasília: Paralelo 15, Rio de Janeiro: Fiocruz, 2011d. p. 409-430.

DEJOURS, C. Addendum: Da psicopatologia à psicodinâmica do trabalho. In: LACMAN, S.; SZNELWAR, L. (Org.). Christophe Dejours: da psicopatologia à psicodinâmica do trabalho. Brasília: Paralelo 15, Rio de Janeiro: Fiocruz, 2011a. p. 57-123.

DEJOURS, C. O fator humano. Rio de Janeiro: FGV, 2003.

DEJOURS, C.; ABDOUCHELI, E.; JAYET, C. Psicodinâmica do trabalho: contribuições da escola dejouriana à análise da relação prazer, sofrimento e trabalho. São Paulo: Atlas, 1994.

DEJOURS, C.; BÈGUE, F. Suicídio e trabalho: o que fazer? Sobradinho: Paralelo 15, 2010. DESSORS, D.; SCHRAM, J. Le travail social. La peur au coeur. Informations Sociales, v. 24, p. 80-90, 1992.

DUARTE, F. S.; MENDES, A. M. Da escravidão a servidão voluntária: perspectivas para a clínica psicodinâmica do trabalho no Brasil.Farol, v. 2, n. 3, p. 68-128, 2015. 
FREITAS, A. P. A.; BORGES, L. M. Tentativas de suicídio de profissionais de saúde: significados possíveis. Psicologia Social, v. 14, n. 2, p. 560-577, 2014.

HOLDSWORTH, N.; BELSHAW, D.; MURRAY, S. Developing A\&E nursing responses to people who deliberately self-harm: the provision and evaluation of a series of reflective workshops. Journal of Psychiatric and Mental Health Nursing, v. 8, n. 5, p. 449-458, 2001 .

LANCMAN, S. O mundo do trabalho e a psicodinâmica do trabalho. In: LANCMAN, S.; SZNELWAR, L. (Orgs.). Christophe Dejours: da psicopatologia à psicodinâmica do trabalho. Rio de Janeiro: Fiocruz, 2011. p. 31-43.

MAISSIAT, G. S.; LAUTERT, L.; PAI, D. P.; TAVARES, J. P. Contexto de trabalho, prazer e sofrimento na atenção básica em saúde. Revista Gaúcha de Enfermagem, v. 36, n. 2, p. 42-49, 2015.

MATTOS, C. B. M.; SCHLINDWEIN, V. L. D. C. "Excelência e produtividade": novos imperativos de gestão de serviço público. Psicologia e Sociedade, v. 27, n. 2, p. 322-331, 2015.

MÁXIMO, T. A. C. O.; ARAÚJO, A. J. S.; SOUZA, P. C. S. Vivências de sofrimento e prazer no trabalho de gerentes de banco. Psicologia: Ciência e Profissão, v. 34, n. 1, p. 96$111,2014$.

MEDEIROS, S. N.; MENDES, A. M. Clínica psicodinâmica do trabalho e CRM: cooperação e relacionamento interpessoal. Revista Conexão SIPAER. v. 4, n. 2, p. 25-44, 2013.

MELEIRO, A. M, A. S.; BOTEGA, N. J.; PRATES, J. G. Manejo das situações ligadas ao suicídio. In: MELEIRO, A.; TENG, C. T.; WANG, Y. P. (Org.). Suicídio: estudos fundamentais. São Paulo: Segmento Farma, 2004. p. 175-192.

MELEIRO, A. M. A. S.; BAHLS, S. O comportamento suicida. In: MELEIRO, A.; TENG, C. T.; WANG, Y. P. (Org.). Suicídio: estudos fundamentais. São Paulo: Segmento Farma, 2004. p.13-36.

MENDES, A. M. B. Aspectos psicodinâmicos da relação homem-trabalho: as contribuições de C. Dejours. Psicologia: Ciência e Profissão, Brasília, v. 15, n. 1, p. 34-38, 1995.

MENDES, A. M.; ARAÚJO, L. Clínica psicodinâmica do trabalho: práticas brasileiras. Brasília: Ex-libris, 2011.

MENDES, A. M.; VIEIRA, F. O. Diálogos entre a psicodinâmica e clínica do trabalho e os estudos sobre coletivos de trabalho e práticas organizacionais. Farol, v. 1, n. 1, p. 144-189, 2014.

NATIVIDADE, M. R. Vidas em risco: a identidade profissional dos bombeiros militares. 
Psicologia e Sociedade, , v. 21, n. 3, p. 411-420, 2009.

PIPKIN, M. La muerte como cifra del deseo: una lectura psicoanalítica del suicidio. Buenos Aires: Letra Viva, 2009.

SILVA, D. R. E. E a vida continua... O processo de luto dos pais após o suicídio de um filho. 2009. 138 f. Dissertação (Mestrado em Psicologia Clínica). Pontifícia Universidade Católica de São Paulo, São Paulo, 2009.

SRIVASTAVA, M.; TIWARI, R. A comparative study of attitude of mental health versus nonmental health professionals toward suicide. Indian Journal of Psychological Medicine, v. 34, n.1 , p. 66-69, 2012.

TAVARES, M. S. A. Suicídio: o luto dos sobreviventes. In: CONSELHO FREDERAL DE PSICOLOGIA (Org.). O Suicídio e os Desafios para a Psicologia. Brasília: Conselho Federal de Psicologia, 2013. p. 45-58.

TEDESCO, S. H.; SADE, C.; CALIMAN, L. V. A entrevista na pesquisa cartográfica: a experiência do dizer. Fractual, v. 25, n. 2, p. 299-322, 2013.

TRIVIÑOS, A. N. S. Introdução à pesquisa em ciências sociais: a pesquisa qualitativa em educação. São Paulo: Atlas, 1987.

TSCHIEDEL, R. M.; MONTEIRO, J. K. Prazer e sofrimento no trabalho das agentes de segurança penitenciária. Estudos de Psicologia, Campinas, v. 18, n. 3, p. 527-535, 2013. VIDAL, C. E. L.; GONTIJO, E. D. Tentativas de suicídio e o acolhimento nos serviços de urgência: a percepção de quem tenta. Caderno de Saúde Coletiva, v. 21, n. 2, p. 108-114, 2013.

WORLD HEALTH ORGANIZATION. Preventing suicide: a global imperative. Luxemburgo: World Health Organization, 2014. 